eCommons@AKU

May 2006

\title{
Abdominal pain with rigidity secondary to the anti- emetic drug metoclopramide
}

Nadeem Ullah Khan

Aga Khan University

Junaid A. Razzak

Aga Khan University

Follow this and additional works at: http://ecommons.aku.edu/pakistan_fhs_mc_emerg_med

Part of the Gastroenterology Commons, Medical Toxicology Commons, Musculoskeletal, Neural, and Ocular Physiology Commons, Nervous System Diseases Commons, and the Stomatognathic System Commons

\section{Recommended Citation}

Khan, N. U., Razzak, J. A. (2006). Abdominal pain with rigidity secondary to the anti-emetic drug metoclopramide. The Journal of Emergency Medicine, 30(4), 411-413.

Available at: http://ecommons.aku.edu/pakistan_fhs_mc_emerg_med/38 


\title{
Selected
}

\section{Topics: Toxicology}

\section{ABDOMINAL PAIN WITH RIGIDITY SECONDARY TO THE ANTI-EMETIC DRUG METOCLOPRAMIDE}

\author{
Nadeem U. Khan, MD* and Junaid A. Razzak, MD $†$ \\ *Section of Emergency Medicine, Department of Medicine, The Aga Khan University, Karachi, Pakistan, and †Department of \\ Emergency Medicine, Emory University School of Medicine, Atlanta, Georgia \\ Reprint Address: Nadeem Ullah Khan, MD, Section of Emergency Medicine, Department of Medicine, The Aga Khan University, P.O. \\ Box 3500, Stadium Road, Karachi 74800, Pakistan
}

$\square$ Abstract-We report a case of abdominal pain with rigidity, mimicking an acute abdomen, caused by metoclopramide, a common anti-emetic drug. Extrapyramidal symptoms are commonly reported side-effects of this medication. They generally include involuntary movements of limbs, torticollis, oculogyric crisis, rhythmic protrusion of tongue, trismus, or dystonic reactions resembling tetanus, etc. Abdominal rigidity due to this medication, resembling an acute abdomen, has not been reported previously. This case report illustrates the importance of considering medication side-effects when evaluating a patient with abdominal pain and rigidity. (C) 2006 Elsevier Inc.

Keywords-metoclopramide; abdominal pain; extrapyramidal symptoms; dystonia; adverse drug effect

\section{INTRODUCTION}

Abdominal pain is a common presentation to the Emergency Department (ED), accounting for 5-10\% of all ED visits (1). It is not always possible to determine the cause of acute abdominal pain in the ED. In fact, as many as $30 \%$ of patients with abdominal pain are discharged without a specific diagnosis, making "nonspecific abdominal pain" the most frequent diagnosis assigned to patients in the ED (2). Although specific diagnosis is not an exception, physicians are expected to identify, with high sensitivity, patients with an acute surgical abdomen. One criterion to clinically diagnose an acute surgical abdomen is to document abdominal muscle rigidity, a sign of peritonitis. We present a case report highlighting drug-induced abdominal muscle rigidity, mimicking an acute abdomen resulting in a serious consideration for laparotomy. The actual cause was a very commonly used medication, metoclopramide (trade name Reglan).

\section{CASE PRESENTATION}

A 27-year-old man presented to the ED with a 3-h history of sudden-onset central abdominal pain. The pain started at rest and was described as moderate-to-severe in intensity, stretching in character, and episodic in nature. There were no exacerbating or relieving factors, including no change with movement, position or breathing. The patient's last meal was $6 \mathrm{~h}$ before presentation to the ED. The patient was passing flatus and his last bowel movement was $8 \mathrm{~h}$ before arrival. He denied any nausea, vomiting, anorexia, urinary burning, frequency or hematuria, and denied any history of trauma.

Three days before this visit he had a high grade fever with temperature of $40^{\circ} \mathrm{C}\left(104^{\circ} \mathrm{F}\right)$ associated with chills and rigors. He also had associated nausea and vomiting. A diagnostic work-up at that time revealed malarial parasites Plasmodium Vivax on a peripheral smear. Forty-eight hours before this presentation, the patient was started on a standard regimen of chloroquin for

RECEIVED: 8 December 2004; FinAl SUBMISSION RECEIVED: 30 March 2005;

ACCEPTED: 26 July 2005 
malaria and standard dose of metoclopramide $10 \mathrm{mg}$ three times a day for nausea and vomiting. Since then, the patient had remained afebrile and the nausea and vomiting was controlled. He took his last dose of metoclopramide $1 \mathrm{~h}$ before the onset of abdominal pain. He denied any other medical problem. He denied any history of alcohol or drug abuse.

On examination, the patient was a lean young man in pain. The initial vital signs were pulse rate of 88 beats/ min, blood pressure $120 / 90 \mathrm{~mm} \mathrm{Hg}$, oral temperature $36.6^{\circ} \mathrm{C}$, and respiratory rate 20 breaths/min. Positive findings on physical examination included blanching erythema of the entire trunk from neck down to the abdominal wall and back and a non-distended tender abdomen with board-like rigidity. There was no rebound tenderness. Bowel sounds were present and normal. The rest of the examination, including chest and lung examination, was within normal limits.

An initial impression of acute abdomen secondary to a perforated viscus was made. The patient received intravenous crystalloid fluid bolus and appropriate laboratory studies were ordered. Surgical consultation was also obtained and morphine and metoclopramide were administered intravenously for pain control. The patient's laboratory results revealed normal hemoglobin, hematocrit and platelet count. The WBC count was 5300 per $\mathrm{mm}^{3}$ with a differential count of $47.2 \%$ neutrophils, $38.9 \%$ lymphocyte, $3.1 \%$ eosinophils and $10.7 \%$ monocytes. Other laboratory studies including serum glucose, BUN, creatinine, and electrolytes were within normal limits. Chest X-ray and supine abdominal X-rays were unremarkable with no evidence of free air or bowel obstruction. Ultrasound of the abdomen revealed no abnormality.

While in the ED, the patient started to complain about the stretching pain in his arm muscles, similar to the pain he was having in his abdomen. Examination of his upper extremities revealed increased muscle tone. With a negative abdominal pain work-up, involvement of upper extremities and a history of being on metoclopramide, a presumptive diagnosis of dystonic reaction was made. The patient was given $5 \mathrm{mg}$ of intravenous Procyclidine (an antiparkinsonian anticholinergic) with marked improvement in his symptoms within minutes, and complete resolution in about 30 min. Repeat physical examination revealed normal vital signs and a completely soft, non-tender abdomen. At that point, the patient was discharged home. Follow-up of the patient over 6 months did not reveal any recurrence of abdominal pain.

\section{DISCUSSION}

Metoclopramide has been used as an anti-emetic since the 1960s and is generally considered safe and effective
(3-5). The anti-emetic properties of metoclopramide are due to its antagonism of central and peripheral dopamine receptors, which is also responsible for many of its adverse effects, including the extrapyramidal symptoms (EPS) (3-6). The EPS occurs in $0.2 \%$ (1 out of 500) patients and manifests primarily as acute dystonic reactions (3-9). The acute dystonia tends to occur in the first 24-48 h of treatment and is seen more frequently in children and young adults and those receiving higher doses used in prophylaxis of vomiting during cancer chemotherapy (3).

Acute dystonia due to anti-dopaminergic drugs is a fairly common presentation to the ED and generally involves face and neck muscles. Although less common presentations such as laryngospasm have been described (3), involvement of abdominal muscles has not been documented in published peer-reviewed literature.

Besides metoclopramide, our patient had been on chloroquin, which is yet another agent causing EPS, with an incidence of 1 in 5000 (10-13). Like metoclopramide, chloroquin-induced dystonia has also been described to involve only the face, neck or limbs and not the abdominal muscles (10-13). Because the patient's symptoms worsened with further doses of metoclopramide in the $\mathrm{ED}$, we believe it is a more likely cause.

Although acute surgical causes of abdominal pain should still be high on the differential diagnosis list, the drug-induced abdominal wall spasms should be considered if the clinical and diagnostic test picture does not fit the pattern of acute peritonitis or acute abdomen. Our patient had normal vital signs, normal WBC count, and normal imaging studies, which decrease the likelihood of an infectious/inflammatory process in the abdomen. The ability to reverse symptoms with drugs like diphenhydramine or benztropine and the potential avoidance of unnecessary laparotomy are good reasons to review medication history and consider this as a possibility if the clinical picture does not make complete sense.

\section{REFERENCES}

1. Powers RD, Guertler AT. Abdominal pain in the ED: stability and change over 20 years. Am J Emerg Med 1995;13:301-3.

2. Simmen HP, Decurtins M, Rotzer A, et al. Emergency room patients with abdominal pain unrelated to trauma: analysis in a surgical university hospital. Hepatogastroenterology 1991;38:27982.

3. Physicians' desk reference, $54^{\text {th }}$ edn. Montvale, NJ: Medical Economics Company; 2000:2603-5.

4. Nobels S. Delmar's drug reference for health care professionals, $1^{\text {st }}$ edn. Clifton Park, NY: Delmar Learning; 2002:571-3.

5. Drug facts and comparisons, $52^{\text {nd }}$ edn. St. Louis, MO: A Wolters Kluwer Company; 1998:2088-94.

6. Tonini M, Cipollina L, Poulzzi E, et al. Clinical implications of enteric and central D2 receptor blockade by antidopaminergic gastrointestinal prokinetics. Aliment Pharmacol Ther 2004;19: 379-90. 
7. Kataria M, Traub M, Marsder C. Extrapyramidal side-effects of metoclopramide. Lancet 1978;2:1254-5.

8. Hagen EM, Farbu E, Bindoff L. Acute dystonia caused by metoclopramide (Afipran) therapy. Tidsskr Nor Laegeforen 2001;121: 2162-3.

9. Cuena Boy R, Macia Martinez MA. Extrapyramidal toxicity caused by metoclopramide and clebopride: study of voluntary notifications of adverse effects to the Spanish Drug Surveillance System. Aten Primaria 1998;21:289-95.
10. Singhi S, Singhi P, Singhi M. Extrapyramidal syndrome following chloroquin therapy. Indian J Pediatr 1979;46:58-60.

11. Achumba JI, Ette EI, Thomas WO, Essien EE. Choloroquineinduced acute dystonic reactions in the presence of metronidazole. Drug Intell Clin Pharm 1988;22:308-10.

12. Osifo NG. Drug-related transient dyskinesias. Clin Pharmacol Ther 1979;25:767-71.

13. Phillips-Howard PA, ter Kuile FO. CNS adverse events associated with antimalarial agents. Fact or fiction? Drug Saf 1995;12:370-83. 